\title{
Developing a New Market Testing Procedure in the Context of Radical Innovation
}

\author{
Mehree Iqbal \\ Department of Marketing and International Business, North South University, Dhaka, Bangladesh
}

Email address:

mehree.iqbal@northsouth.edu

To cite this article:

Mehree Iqbal. Developing a New Market Testing Procedure in the Context of Radical Innovation. Communications. Vol. 3, No. 5, 2015, pp. 120-127. doi: 10.11648/j.com.20150305.17

\begin{abstract}
In the context of radical innovation the conventional market testing procedures seems ineffective to generate sufficient profit for the company and satisfy consumers need. Moreover, the alternative approaches lacked some features to successfully prototype testing. So, the gap between the literature and the real life application leads towards producing a radically new approach for market testing. Therefore, sole aim of this research was to produce an effective market testing procedure in the context of radical innovation. To produce a new testing procedure an extensive research has been done based on document research methodology on the alternative approaches such as Open Innovation, Lead User method, Delphi Technique and Product Bundling. The new procedure has been divided into two categories based on target market- one focuses on the mass consumers and the other on the expert consumers. The categorization was important as literature demonstrated that consumers perceive and behave differently when considering radically new products. The new procedure sheds light on the complexity of understanding consumer needs and technological innovation. The firms can use this procedure to effectively generate useful feedback before commercializing their radically innovated products.
\end{abstract}

Keywords: Market Testing, Radical Innovation, Open Innovation, Lead User Method, Delphi Technique

\section{Introduction}

Radical innovation is a product, process or service with either unprecedented performance features or familiar features that offer significant improvements in performance that transform existing market or create new ones [23]. According to [32], the leading edge of radical innovation tends to dominate world markets and promote the international competitiveness. Thus, radical innovation simultaneously drives market growth, firms' success, and nations' economic growth. Moreover, Radical product innovations are those that satisfy a new need through the utilization of a new technology or one not yet applied in that form [19]. The rapid innovation across countries overlaps with entrepreneurial behavior. The characteristics of radical innovation are somewhat similar to entrepreneurship orientation as it also focuses on pioneering innovations which pre-empts competition $[1,3,4,20]$. In conventional process, the companies use standard controlled and simulated test marketing for consumer products and for the industrial products. These processes strongly depend on the responses of the consumers and these development processes are based on the notion of incremental innovation [33]. However, it does not include the context of radical innovation where the market and technology both are uncertain.

There has been no process considering radical innovation where the technology and market both are well understood. It is doubted whether the standard approaches will work for market opportunity analysis in this particular scenario. However, there are alternative approaches such as Open Innovation, Lead User (LU) and Visioning Technique has been widely used for idea generation for radical innovation. However, Open Innovation yet not used strongly on most of the industries due to its nature which fully oppose to the conventional market testing procedures. Though LU method can generate innovative and appealing new product concept, it is not yet commonly used for market testing. The method tends to be very successful for idea generation compared to test marketing. For Visioning Techniques the success of the approach is dependent on factors such as- expert selection, inquiry structure and data quality. All these factors can lead to bias result which directs to misleading findings for radical innovation. So, this paper is important and will add value to market research as there is inadequate literature available on market testing procedures for radical innovation. Therefore, a 
new radical procedure for market testing is needed to answer the question, how do we effectively commercialize radically innovated products?

\section{Literature Review}

This section seeks the remedy of the problems of conventional testing for radical innovation by analyzing the literature. The objectives such as addressing context of the complex innovation and reviewing current approaches have been fulfilled by thorough analysis of conventional testing and the problems associated with it along with alternative approaches; Open Innovation, Lead User, Visioning Technique and Product Bundling used for radically innovated products. These approaches will lead to creating a new effective market testing procedure.

\subsection{Conventional Testing}

The conventional product development process is a simple linear model where test marketing is a step before commercializing the product. The basic idea of market testing is to assess the consumer response in a limited way in the market place before the new product is launched. For the industrial products the test marketing strongly depends on consumer response using distributor and dealer display rooms, trade shows and standard or control test marketing. Also, customer participation is considered to address the trade-off between new product innovativeness and diffusion to market [16].

Conventional testing focuses on product development rather than market development. According to [28], conventional techniques focuses on product level problems (idea generation) rather than market level. Moreover, conventional market research discourages radical innovation due to the consumer dependency attitudes towards familiar products. [15]. It has been argued that to have a proper evaluation of the market needs, the customer should be aware and able to specify their preferences. This view has been supported by [11] and they identified the common technique used for consumer responses include survey, in-depth interview, observation technique and focus group. These techniques focus on capturing consumer's previous experience with the available products or services of the company. Practical experience shows that direct research with customers and users delivers good results for incremental innovations; whereas, for radical innovations the results are usually unusable $[18,19,42]$.

\subsection{Specific Challenges in Radical Innovation}

The main challenge with radical innovation is the lack of knowledge regarding innovation for both the firm and consumers. This innovation is not only new to the firms but also for the market. In that case the customer will not be able to express their requirements for such product that opens entirely new markets and applications [28]. For radical innovation [38] demonstrated that current market research are not reliable as the perceptions for the radical products are not controlled by the marketers and users own real-world experience. Moreover, for radical innovations the traditional testing is not well suited and leads to wrong product introduction to wrong consumers at the wrong times [34, 35]. To support the uncertainty related to radical innovations (Breakthrough Products) and the incapability of conventional testing finding the right consumer who will drive the radical innovation is a crucial factor [22, 23]. Even though, market testing helps answering the questions on recognizing potential customer, product functionality and the needed infrastructure to support the radical innovations. However, it doesn't abolish the confusion and misconception of how to deal this situation or how to get the future acceptance, demand or sales prediction [11]. The market information need of radical innovation projects is orientated mostly towards the future [19].

\subsection{Alternative Approaches Used in Radical Innovation}

In recent years, to somewhat cope with the radical innovation a considerable amount of literature has been developed on alternative approaches. This research will be strictly focused on the most popular and effective alternative testing procedures used for radical innovation.

\subsubsection{Open Innovation Model}

Open innovation is a model which enables the firms to develop both internal and external ideas to help innovate and sustain in the market. Open innovation model has been developed for free sharing of information to cope with uncertain situations such as radical innovation [7, 8]. For capturing innovation and opportunities, firms take ideas from various internal units such as $\mathrm{R} \& \mathrm{D}$, marketing, after-sales service etc. However, firms also rely on external sources in selecting the best possible alternative to create new opportunity and innovations for sustenance in the long run $[8$, $41,36]$. As the name suggests, this model redefines the firms and its environment boundary. This model suggests openness towards different networks and work collectively to commercialize new knowledge [26]. The advantages using this model includes: encouraging competition amongst the solvers, only pay if the innovation was successful, the issue is solved by only those who have the relevant expertise in the field and increase the ability and capacity to generate more ideas [36]. This model enables the firm to not only save the cost but also capture the best possible outcomes from various expert sources. For developing a market testing procedure this model can open a whole new concept as it helps overcome the organizational myopia [41]. Moreover, another model is relevant to open innovation process which follows on linking networks to gather more relevant information. It is called the network model which emphasis on linking external source along with the internal source to contribute more on product's perception in the market and it is an accumulated process that requires inputs from wide variety sources $[13,33]$.

In open innovation process the seekers (companies) have to provide the requirements of what they are looking for or 
expecting and the solvers (free-lancers) through their various networks offer the solution to it. It directs to a new trend for firms to outsource or off-shore the innovation- related activities $[9,10]$. These solvers help identifying the best possible outcomes for the potential market [8]. Then seekers usually buy or patent the best possible solutions from them and utilize it [40]. It is widely used for idea generation rather than test marketing.

\subsubsection{Lead User Method}

Lead User method identified the need of consumer participation as co-developer to innovate new product and recommended using this method in new product development (NPD) process for innovating products [16, 27]. According to [41], this method is not a traditional market research where the customer is asked what they want rather this method identifies what market most advanced users understands for the new product innovation for the future of the business [12]. Lead user are the consumers who (1) anticipate relatively high benefits from obtaining a solution to their needs and (2) are at the leading edge of important trends in a marketplace [38]. To further explain, the best solution for the market can be provided by the lead user as they face needs that will be general in the marketplace but face them months or years before the mass consumers of that marketplace encounters them. They also positioned to benefit significantly by obtaining a solution to those needs [14, 19].

For the radical innovation, lead user method seems to be rational. As in the field of rapid change and complex product development, the productivity can be improved by lead user through the analysis of need and solution. Also, product concept developed by lead users had greater appeal in the marketplace than the concepts developed by conventional marketing research methods for industrial software [37]. LU method has the potential to use for test marketing for radical innovation as the lead users can be integrated into prelaunch stages such as prototype testing phase. In particular, to transform radically new concepts into initial prototypes and marketable products lead users establish and manage the required innovation networks [24, 25, 39].

The procedure for conducting Lead User method consists of four phases. The first two phases identifies the customer needs and the last two phase focus on the solution to satisfy needs addressed. The process takes up to six to eight months to successfully complete and conducted by a team consisting six to eight people. The team members are from combination of cross functional units with strong selfmotivation and confidence. However, there is a team leader who acts as an instructor having sufficient knowledge and flexibility [12]. In the first phase the team members prepare to launch lead users by defining the focus of the study and overall goal, selecting the leader, analyzer etc., time requirements and planning the activities and role of the team members. On the second phase they identify trends and customer needs through various sources such a literatures, interviews etc. After scanning and intensive networking they come to the conclusion of identifying lead users. In the third phase, team members explore the needs of lead users by inviting them to a long workshop and after that they conduct interviews where they ask unstructured open ended questions to get most out of the lead users. After this, team gets the general feedback on the needs and probable solutions. It leads to the last phase where the members improve the concepts with lead users and experts. In this phase, they design the specification for the new products or services, ideas on how to implement and further develop it. Successfully complete of these phases can lead to radical innovation of new product or service which will create new market for the firm [6].

However, there are challenges involved in this method which include finding the right people, remaining open minded about the problems and enough allocation of time for the process. To have the best outcome, this issues needs to be resolved [12].

\subsubsection{Visioning Techniques}

Visioning techniques focus on information gathering and analyzing rather than focusing on the customer or product. It identifies the key aspects of the future environment and trends of the business. For the launch of radical innovations, it offers unique disciplined approaches for the on-going management to have competitive intelligence [11]. The unique approaches are Delphi and Back-casting. Delphi approach is the scenario analysis approach where else Back-casting approach can be limited to researchers control [21]. Therefore, to be specific on the objective of the research Back-Casting technique has not been discussed further and the paper focuses on the Delphi technique for the relevancy.

Delphi technique is one of the approaches for identifying future environment and trends of the business through gathering and analyzing information. It is a structured communication technique which relies on a panel of experts [11]. This technique was developed by RAND Corporation for U.S. Air force for their operation in 1950s and the aim of the technique was to have expert opinion on specific issue [29]. The interactive session with the experts helps gather information which leads to forecasting of the sales of the products.

This technique can be modified to fit into any situation. The advantages for this method include high flexibility due to the dependence on experts; the experts can generate different options and alternatives to cope with the situation; the forecast of this technique are dynamic compared to other quantitative methods. Moreover, Delphi method is comparatively simple and cost effective and capable of generating new ideas [5]. This method enables large number of participants from various geographical locations. Moreover, four key features are anonymity, iteration, controlled feedback and analysis of this technique. The procedure of Delphi technique is to obtain the group response of the experts which is most reliable statistical 
summary and the consensus of the opinions are the comprising of mean or median value which is calculated through intensive questionnaire combined with average estimation of the group response in a controlled opinion feedback [29]. The key features of this technique help abolishing biasness, increase reliability of the technique. For the context of radical innovation which is a must. Delphi method can be used as an interactive, structured process to consolidate the opinions of expert groups and is based on three basic assumptions of judgment: group results are more accurate than individual results, expert groups perform better than layperson groups and controlled and anonymous feedback of the group opinion leads to converging individual responses. Delphi studies have been useful in forming guidelines, standards, and in predicting trends. It is a method for predicting future events and for generating a quick consensus by anonymous survey [21].

\subsubsection{Product Bundling}

Product bundling is a new approach which facilitates the adoption process of consumers by bundling the radically new product with an existing one. The research has suggested that perception to adopt radically new product is comparatively low due to lack of prior knowledge of consumer. As consumers prior knowledge affect the adopting behavior so, bundling the radical new product with familiar product will increase the chances of adoption [30]. Moreover, the research suggested that product bundling enhanced the new products evaluation and adoption intention. To reduce consumer educating cost in terms of radical innovation product bundling works effectively [13]. However, for experts the bundling does not make any difference to their perception. This approach motivates the target consumers with little or no knowledge regarding radically innovated products. For developing new market testing procedure this approach will add value to the process for customer centric specific industry.

\subsection{Research Setting of the Study}

The sole aim of this paper is to develop a procedure for market opportunity assessment for radically innovated products. The available procedures for market testing are insufficient so this paper will provide companies/businesses with more practical and effective means for commercializing radically innovated products globally. The specific objectives of this paper include:

- Reviewing current approaches for market testing in radical innovation which will add value in developing a new testing procedure.

- Critically addressing the context of complex innovation which will provide insight idea of conventional market testing and alternative approaches used.

- Synthesizing the existing knowledge to arrive at a model which means combining all the information gathered and analyzed to create the new model.

\section{Methodology}

Documentary research method has been used in this paper to investigate on the current scenario of radical innovation and how the most relevant procedure can be developed. The paper is based on induction process as it will proceed on the basis of gathered data to the final finding on creating a new theory on market testing procedure for radical innovations. [31]. The data analysis relied on theoretical orientation as it focuses on certain data and guides the analysis following the proposed theories [43]. The documentary research method is used in investigating and categorizing written documents to support the viewpoint or argument of an academic work. The process of documentary research involves some or all of conceptualizing, using and assessing documents [2]. According to [2], documentary research is beneficial as it is cost effective, readily available data, saves time and nonreactive. Compare to survey, in-depth interview or observation method it is quite easier to follow and implement. For this research paper, qualitative data has been used which made the analysis straightforward, accurate and unbiased [2].

\subsection{Data Collection Technique}

The data collection technique was primary analysis of secondary data which includes both internal and external sources. The data has been collected from different sources including library, internet and various databases. To ensure the authenticity, reliability and validity of the sources most of the journal articles are ABS Four graded and some of very relevant articles are Three graded. Other secondary sources are books, reports which are strictly relevant to the paper. To ensure quality of the paper most relevant theories such as Open innovation, Lead user and Delphi technique, Bundling have only been used through various journals and books. All the data has solely collected by the author of this paper. The journals used in the paper are not more than 15 years old. However, to fulfill the analysis requirement a few older journals have been considered for better understanding of the origin of the theories and procedures.

\subsection{Data Analysis}

To develop the market testing procedure in the context of radical innovation, first relevant literature review has been derived from the qualitative data, which means systematically analyzing it so as to tease out themes, patterns and categories. There is no single right way to do the data analysis or no single methodological framework for documentary research [2]. Therefore, a method of data analysis was systematic and well structured. The data was analyzed by relying theoretical propositions. The analysis helped to overcome the lacking of the processes mentioned in the literature review and helped thinking critically and build new concept to create an effective procedure [43]. As the context of this research is different so, strictly focusing on certain data was needed and the new procedure needed 
to be a combination of the proposed theories. Moreover, comparing the trends helped overcoming the limitations reflected in the procedures of the existing methods used in radical innovation.

\section{Proposed Research Model}

After synthesizing all the existing knowledge based on the literature a new market testing procedure has been developed. In the marketing testing stage as the product has been developed already, the marketer will only concentrate on getting consumers feedback on the viability of the product. The new market testing procedure is divided depending on target consumer types. It will focus on network model to generate feedback from the consumers. This model will be successful in real life as it is a combination of all the existing techniques used for radical innovation. Moreover, this model strictly focused on eliminating the shortcoming and utilizing the usefulness of the alternative approaches. It will be solely used on market testing rather idea generation. This is a dynamic model which considers all the aspects of radical innovation and different target markets.

\subsection{The New Market Testing Procedure for General Consumers}

This market testing procedure is for the general consumers. When the radically innovated product's target consumers are the mass population companies will use this procedure. The company will create an interdisciplinary team as suggested in Lead User method. Delphi method will also be used to identify the targeted users through research on factors such as- previous purchase history of similar product category, loyalty of the customer towards the company, spending behaviour etc. As the radically innovated products are global product so the consumers will be divided by the allocated location. Then for getting proper customer feedback, the radically innovated product will be bundled with a product which was popular amongst those consumers. The bundling product's category might complement each other. After thorough research on targeted consumers, the team will start cold calling or social media campaign to the target customers. The aim of this call or message is to motivate the customers to participate in an online questionnaire and as motivation a gift voucher can be provided to the most potential participants. This online questionnaire will be focused on the bundling product. It will give the consumers' confidence to complete the questionnaire.

The most potential customers will be segmented after getting the feedback. The indicators for selection will be the strong motivation to accept new product, motivated to experience change and willingness to participate. Then the most potential customers will be emailed with a vague new product description along with the gift voucher as promised before. Moreover, in the email a time slot will be provided to select the most convenient time for the telephonic interview. As the method is conducted via internet the team can conduct this procedure in various locations. Next, the potential consumers will be called for the interview. The in-depth telephonic interview will be conducted based on the radically new product. After conducting all the interviews the team will analyse the feedbacks and produce a result for product acceptance and viability in the respected market. This procedure might take up to 1 to 3 months based on consumer response. However, the result of this procedure will provide the company with the most reliable, authentic information regarding the sales forecast and which location to sell more first.

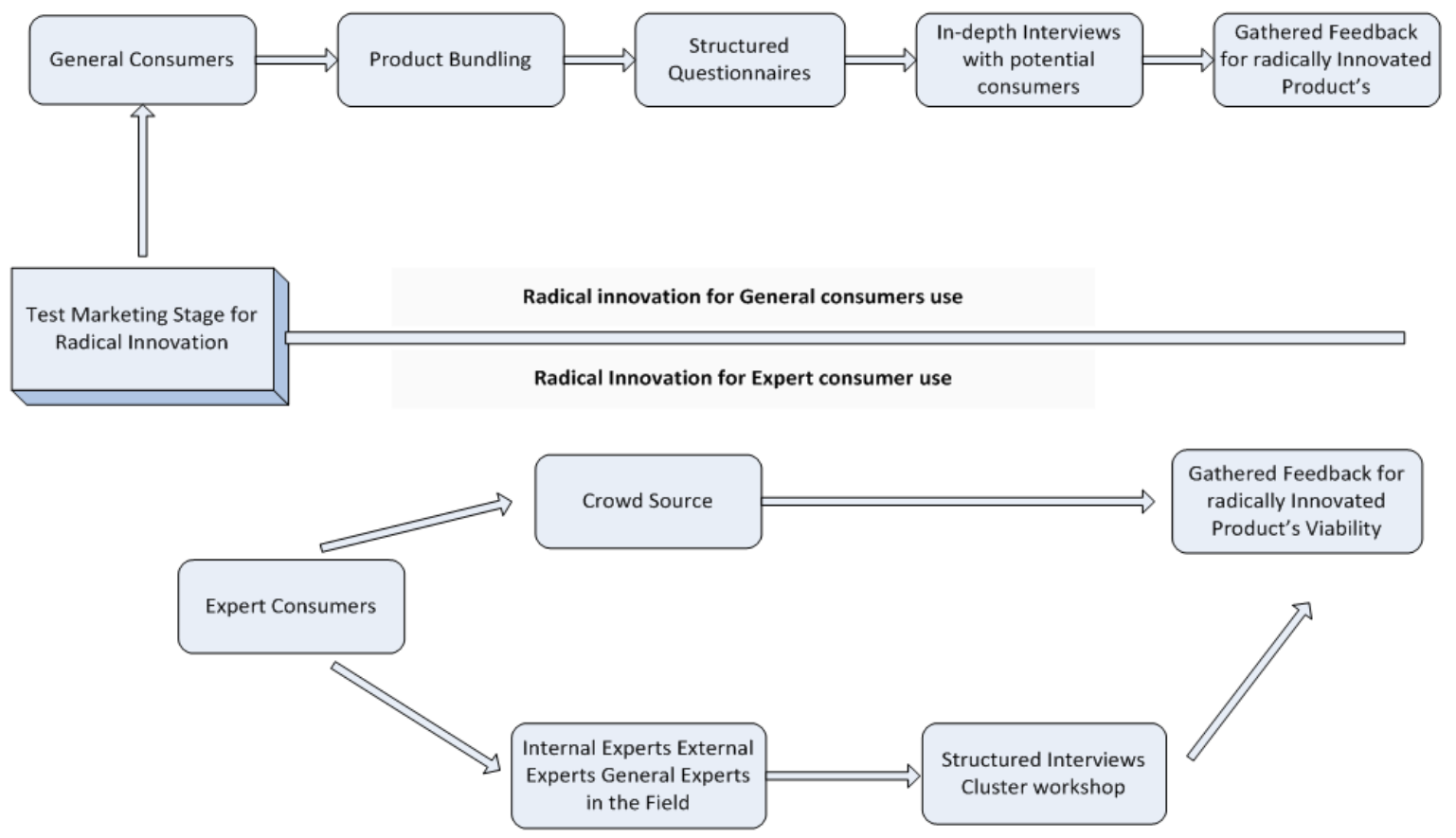

Figure 1. New Market Testing Procedure in the Context of Radical Innovation. 


\subsection{The New Market Testing Procedure for Expert Consumers}

When the radically innovated product's target consumers are in the same field with skills and competencies then this new market testing procedure will be used. To start this procedure the company will create a cross functional team as suggested in Lead User method and identify the targeted consumers. The targeted consumers will be selected based on network model. The respondent for interview and cluster workshop will include internal experts, external experts and general experts in the specific field. Based on company's current consumers and expected consumer's profile the experts will be selected by the team. The internal experts will be used to anticipate the future threat and limitation of the innovated product. This will help to handle the query of the other experts. The team will first email a vague description of the radically innovated product and seek permission for telephonic interview with the experts. Then they will conduct semi-structured interviews with the experts. After completing the interviews the feedbacks will be shared with the internal experts to analyse the product viability. Then from the analysis most potential consumers will be selected and segmented based on the location. Then a small workshop will be held by the company to provide specific product specification and various queries of the experts will be answered in the workshop. The workshop will be conducted by clusters of experts and the team will select the experts cluster based on the similar preference to avoid conflict of interest amongst the experts working in competitor companies.

Moreover, the company will also crowd source to explore new consumers and dimensions in the market for the radically innovated product. Crowd source is similar to open innovation approach and can add great value to the market testing procedure. There are online crowd sourcing organization where the company needs to provide the information and requirement of the research only by providing a fee. They will provide the information regarding market viability of the innovated products by various related sources. After conducting both the operation the team will analyse the final result and make the final recommendation to the company regarding product viability and acceptance in the market. This procedure might take up to 3 to 6 months based on expert consumer response. However, the result of this procedure will provide the company with the most reliable, authentic information regarding the sales forecast, viability, lucrative target market location.

\section{Discussion and Implications}

Therefore, it can be stated that the results of this paper showed positive correlation with the literature. The major findings were that there is no single right alternative approach to conduct market testing in the context of radical innovation. While analyzing the techniques and the limitations of the alternative approaches were demonstrated. The new market testing procedures have been produced as a remedy to the currently practiced testing procedure. In addition, this procedure has used the strength of all the alternative approaches and abolished the limitations associated with it. The objective of the paper has been fulfilled by reviewing the current approaches in the contest of radical innovation such as- Open Innovation, Lead User Method, Visioning Technique and Product Bundling. Also, the problem associated with recent market testing procedures in context of radical innovation has been addressed. Moreover, the new market testing procedures have been developed based on the current literatures. This is the only market testing procedure were different target customers were taken into account and different market testing procedures were developed focusing on it.

The new market testing procedure can be used in any industry where radical innovation takes place. The innovated product targeted towards general consumers and expert consumers both can use this procedure to effectively test the market. The company can use this method to get the most out of the consumers as it focused on both types. However, for general consumers the Product Bundling approach along with online questionnaire will motivate the consumers to participate. For the expert consumers along with diverse group of experts, the crowd sourcing used to add new dimension to the product's market viability. This procedure will help avoiding biasness and produce the actual results due to the use of diverse group of experts and combining Delphi technique with open innovation. Only for market testing purpose the procedure can be used and the nature of the process helps to get global consumers response. This procedure might take up to 1 to 6 months based on target consumers' response. This procedure might seem a lengthy procedure to conduct but this procedure will surely ensure the accuracy, authenticity of the result. This will help the companies to decide on which location to focus first to launch product, sales forecasting, on what scale to promote and what strategy to follow for pricing. To conclude, the new market testing procedure is a dynamic, flexible and reliable method which can be used to get the market viability and acceptance of the radically innovated product.

\section{Limitations and Future Research Direction}

The limitation of the study is the dependency on the literature. There are very less data for market testing procedures. All the data gathered in literature under radical innovation are based on the idea generation or product innovation. Moreover, it is very difficult to approach and gather the insight information of the companies developing radical innovation. As a result it was not possible to experiment the procedure in the companies developing radically innovated products. 
The aim of the study was to develop a new market testing procedure in the context of radical innovation. So, future research is necessary to practically test the procedure. The new testing procedure has been developed based on literature. The procedure is compatible with literature but there is no way to prove it without using in real life. In the radical new context where no specific guideline was given, this method will add value. The businesses can learn a new approach for their radically innovated products using this method. Therefore, future research should be done practically implementing the procedure in real business.

\section{References}

[1] Atuahene-Gima, K. and Ko, A., [2001]. An Empirical Investigation of the Effect of Market Orientation and Entrepreneurship Orientation Alignment on Product Innovation. Organization Science. 12 (1). 54-74.

[2] Ahmed, Jashim Uddin [2010]. 'Documentary research method: New dimensions', Indus Journal of Management \& Social Sciences. 4(1), 1-14.

[3] Autio, E., George, G. and Alexy, O., [2011]. International Entrepreneurship and Capability Development-Qualitative Evidence and Future Research Directions. Entrepreneurship Theory \& Practice.

[4] Bessant, J. and Tidd, J., [2009]. Innovation and Entrepreneurship. 2nd ed. John Wiley \& Sons Ltd.

[5] Bogers, M., Afuah, A. and Bastian, B., [2010]. Users as Innovators: A Review, Critique, and Future Research Directions. Journal of Management, 36 (4), pp.857-875.

[6] Churchill, J., Von Hippel, E., and Sonnack, M., [2009]. LeadUser Project Handbook: A practical guide for lead user project teams. Downloaded from http://web.mit.edu/evhippel/www/tutorials.htm

[7] Chesbrough, H., [2004]. Managing Open Innovation. Research Technology Management, 23(1)

[8] Chesbrough, H., [2003]. An Era of Open Innovation. MIT Sloan Management Review.

[9] Chesbrough, H. and Appleyard, M., [2007]. Open Innovation and Strategy. California Management Review, 50 (1)

[10] Chesbrough, H.,[2010]. Business Model Innovation: Opportunities and Barriers. Long Range Planning. 43, 354363.

[11] Deszca, G., Munro, H. and Noori, H., [1999]. Developing breakthrough products: challenges and options for market assessment. Journal of Operations Management, 17, 613-630

[12] Eisenberg, I., [2011]. Lead-User Research for Breakthrough Innovation. Research Technology Management.

[13] Enkel, E., Perez-Freije, J. and Gassmann,O. [2005]. Minimizing Market Risks through Customer Integration in New Product Development: Learning from Bad Practice. Creativity and Innovation Management, 14(4)

[14] Franke, N., Von Hippel, E., and Schreier, M., [2006]. Finding Commercially Attractive User Innovations: A Test of Lead-
User Theory. Journal of Production Innovation Management, 23, pp.301-315.

[15] Franke, N., Keinz, P. and Steger, J. C., [2009]. Testing the Value of Customization: When Do Customers Really Prefer Products Tailored to Their Preferences? Journal of Marketing, $73,103-121$.

[16] Fang, E., [2008]. Customer Participation and the Trade-Off between New Product Innovativeness and Speed to Market. Journal of Marketing, 72, 90-104.

[17] Green, R. [2014]. The Delphi Technique in Educational Research. SAGE Open. DOI: 10.1177/2158244014529773

[18] Gassmann, O., [2006]. Opening up the innovation process: towards an agenda. $R \& D$ Management, 36, 3 .

[19] Herstatt, C., [2004]. Market research for radical innovation. International Journal of Entrepreneurship and Innovation Management.

[20] Jones, M.V., Coviello, N. and Tang, Y.K., [2011]. International Entrepreneurship Research (1989-2009): A Domain Ontology and Thematic Analysis. Journal of Business Venturing.

[21] Keller, J., H.A. von der Gracht [2013]. The influence of information and communication technology (ICT) on future foresight processes - Results from a Delphi survey. Technological Forecasting and Social Change. Doi:10.1016/j.techfore.2013.07.010.

[22] Koberg, S.C., Detienne, R. D., and Heppard, A. K., [2003]. An empirical test of environmental, organizational, and process factors affecting incremental and radical innovation. Journal of High Technology Management Research, 14, 21-45.

[23] Leifer, R., O'Connor,G. C. and Rice, M., [2001]. Implementing radical innovation in mature firms: The role of hubs. The Academy of Management Executive, 15 (3), 102.

[24] Letti, C., Hienerth, C., and Gemuenden, H., [2008]. Exploring How Lead Users Develop Radical Innovation: Opportunity Recognition and Exploitation in the Field of Medical Equipment Technology. IEEE International Transactions Journal of Engineering Management, 55(2),219-233.

[25] Lettl, C., Herstatt, C., and Gemuenden, H., [2006]. Users contributions to radical innovation: evidence from four cases in the field of medical equipment technology. $R \& D$ Management Journal, 36(3).

[26] Laursen, K. and Salter, A., [2006]. Open for innovation: the role of openness in explaining innovation performance among U.K. manufacturing firms. Strategic Management Journal, 27, 131-150.

[27] Olson, E. L. and Bakke, G., [2001]. Implementing the Lead user method in a high technology firm: A longitudinal study of intentions versus actions. The Journal of Product Innovation Management, 18, 288-395.

[28] O'Connor, G.C., [1998]. Market Learning and Radical Innovation: A Cross Case Comparison of Eight Radical Innovation Projects. Journal of Product Innovation Management, 15, 151-166.

[29] Rowe, G. and Wright, G., [1999]. The Delphi technique as a forecasting tool: issues and analysis. International Journal of Forecasting, 15, 353-375. 
[30] Reinders, M. J., Framback, R.T. and Schoormans, J., P., L., [2010]. Using Product Bundling to Facilitate the Adoption Process of Radical Innovations. Journal of Product Innovation Management, 27, 1127-1140

[31] Saunders, M., Lewis, P. and Thornhill, A., [2006]. Research Methods for Business Students. 4th ed. Oxford: Pearson Education.

[32] Tellis, G., Prabhu, C. \& Chandy, R. [2009]. Radical Innovation Across Nations: The Preeminence of Corporate Culture. Journal of Marketing.73, 3-23.

[33] Trott, P., [1998]. Innovation Management \& New Product Development. Harlow: Financial Times Management.

[34] Talke, K. and Hultink, J. E., [2010]. The Impact of the Corporate Mind-set on New Product Launch Strategy and Market Performance. Journal of Product Innovation Management, 27, 220-237.

[35] Talke, K. and Hultink, J. E., [2010]. Managing Diffusion Barriers When Launching New Products. Journal of Product Innovation Management, 27, 537-553.

[36] Terwiesch, C. and Xu, Y., [2008]. Innovation Contests, Open Innovation, and Multi agent Problem Solving. Management Science, 54 (9), 1529-1543
[37] Urban, G. L., and Von Hippel, E., [1988]. Lead user analyses for the development of new industrial products. Management Science, 34 (5), pp.569-582.

[38] Von Hippel, E., [1988]. Lead Users: A Source of Novel Product Concept. Management Science, 32(7).

[39] Von Hippel, E., Churchill, J., and Sonnack, M., [1998]. Breakthrough Products and Services with Lead User Research. Carnbridge and Minneapolis: Lead User Concepts, Inc.

[40] Von Hippel, E., [2001]. Innovation by user communities: learning from open- source software. MIT Sloan Management Review

[41] Von Hippel, E., [2005]. Democratizing Innovation. Cambridge, MA: MIT Press.

[42] Witell, L., [2011]. Idea generation: customer co-creation versus traditional market research techniques. Journal of Service Management. 22 (2), 140-159.

[43] Yin, R.K., [2003]. Case Study Research.Design and Methods. 2nd ed. Sage Publications. 